\title{
Sitting on the FENSA: WHO engagement with industry
}

\author{
Kent Buse, PhD and Sarah Hawkes, PhD
}

When decisions are made that will impact on people's health, who should be represented at the policy-making table? Is it sufficient to rely upon representatives from national governments (the State), or should other stakeholders participate - and if so, to what purpose? To advise? Make decisions? Or as funders? These issues lie at the core of a governance debate ${ }^{1}$ that has been rancorously discussed in relation to WHO for several years. In May 2016 the World Health Assembly (WHA) reached consensus: "WHO engages with non-State actors ....to encourage [them] to...protect and promote public health" - and considered non-State actors as "nongovernmental organizations [NGOs], private sector entities, philanthropic foundations and academic institutions"2.

The resolution known as FENSA (Framework of engagement with non-State actors) had a long and difficult gestation, but is seen by many as a critical element of the ongoing WHO reform. Members States were generally supportive of the Framework, but NGOs voiced concern that "FENSA will increase.....problematic entanglements between WHO and powerful private sector actors", and were disappointed that the Framework fails to "acknowledge the different nature - and thus different roles - public and private sector actors should play in global health governance" ${ }^{3}$. In contrast, the private sector International Federation of Pharmaceutical Manufacturers and Associations welcomed the framework as giving "an equitable voice to a vibrant community of public and private organizations whose shared goal is to make this world healthier"4.

Concerns have long been raised about potential and actual conflicts of interest arising from WHO's engagement with non-State actors (NSA), particularly those whose mandate hinges 
foremost upon the pursuit of profit rather than public health. WHO has acted upon these concerns in the past, and has not, for example, engaged with the tobacco or arms industries. The existence of conflicts of interest policies in WHO have not prevented problems arising. A Reuters investigation, for example, found not only that regional office PAHO had accepted money from companies such as Coca-Cola, Nestle and Unilever, but also that at least two of the 15 members of WHO's Nutrition Guidance Expert Advisory Group had direct financial ties to the food industry ${ }^{5}$. The flow of people between the private and public sector, including secondment to WHO, raises questions of influence and impartiality. Philanthropic foundations can also have an influence and potential conflicts of interest. For example, the charitable UN Foundation placed a staff member in the WHO Director General's office for a 2-year period; and the Gates Foundation seconded a manager to the WHO Polio and Emergencies Cluster6.

The FENSA resolution recognizes and elevates the issue of the potential conflict of risk (including undue influence in setting/applying policies/norms/standards) from engagement with NSA and proposes mechanisms to avoid and manage these risks in the interests of public health - including through transparency, enhanced procedures and staff training. Moreover, the resolution sets out specific guidelines in relation to engagement with each category of NSA.

FENSA is a necessary but insufficient response to the significant part the private sector plays determining population level health outcomes. FENSA specifically namechecks the biggest threat to human health (noncommunicable diseases, which are now the world's leading cause of disability and death), but does not go so far as to propose any mechanisms by which the private sector's actions in the production and marketing of commercial products can and should be governed. The links between the pursuit of profit and negative health outcomes associated with processed foods, alcohol, tobacco, air pollution, have been extensively described ${ }^{7}$. WHO could have used the opportunity to leverage its mandate and authority to address the larger issue of governing the activities of industry, but FENSA focuses narrowly on the questions of risk assessment and management for WHO itself when engaging with the private sector. We are concerned that due diligence to protect brand WHO, even if well implemented, will not necessarily translate into better behaved industries 
at global and national levels that will act to protect and promote the health of their consumers.

The relationship between public and private authority sits at the core of how we achieve NCD-related goals, and the governance of commercial determinants is crucial. Do we rely upon self-regulation by industry (e.g., marketing codes or voluntary initiatives to reduce harmful exposure), co-regulation of the activities of industry (e.g. public sector partnerships with the private sector are an overarching approach within of WHO's 2013-2020 Global Action Plan on $\mathrm{NCDs}^{8}$ ), or public regulation of private sector activities. The latter approach is frequently promoted by experts as the preferred option - for example, in relation to the UK's Responsibility Deals, the President of the UK Faculty of Public Health wrote that "There is no evidence that the 'softly softly' approach of engaging with industry rather than using legislation to improve people's health has been more effective or quicker.......sometimes the state has to step in to protect people." ${ }^{\prime 9}$ Nonetheless, governance scholars note that problems of enforcement and industry subversion ${ }^{10}$ of public health goals raising the question of the effectiveness of this model.

WHO and its governing body have taken an important step in democratizing the invite list to the policy table and establishing the dining etiquette. Now WHO needs to jump decisively off the right side of the fence and take more impactful measures, globally and nationally, to protect the health of the public by aggressively supporting governments and their partners to govern the health impact of Big Industry. This will entail a shift from treating this as a technocratic and managerial project to the political one that it patently is. A small but not insignificant part of the project entails embracing the public interest NGOs, which it has too long treated as adversaries, as the partners it needs to generate both public support and political incentives to induce national leaders to act.

\footnotetext{
${ }^{1}$ Bexell M, Tallberg J, Uhlin A. Democracy in Global Governance: The Promises and Pitfalls of Transnational Actors. Global Governance 2010;16:81-101.
} 
${ }^{2}$ World Health Organization. Framework of engagement with non-State actors. Sixty-ninth World Health Assembly, Agenda Item 11.3. Available at:

http://apps.who.int/gb/ebwha/pdf files/WHA69/A69 ACONF11-en.pdf

Accessed 30/06/16

${ }^{3}$ Lhotská L, Gupta A. Whose health? The crucial negotiations over the World Health Organization's future. Available at: http://www.policyforum.net/whose-health/

Accessed 29/06/16

${ }^{4}$ Statement from International Federation of Pharmaceutical Manufacturers Associations, May 2016. Available at: http://www.ifpma.org/wp-content/uploads/2016/05/IFPMAStatement-11.3-NSA-May-2016-final.pdf Accessed 29/06/16

${ }^{5}$ Wilson D, Kerlin A (2012). Special Report: Food, beverage industry pays for seat at healthpolicy table. Reuters, 19 October 2012. http://www.reuters.com/article/2012/10/19/usobesity-who-industry-idUSBRE89I0K620121019 [Accessed 30/06/2016].

${ }^{6}$ Third World Network, December 2015. WHO: Unease over seconded philanthropic foundation staff to top management. Available at http://www.twn.my/title2/health.info/2015/hi151202.htm Accessed 29/06/16

${ }^{7}$ Stuckler D, Nestle M. Big Food, Food Systems, and Global Health. PLOS Medicine, 2012. http://dx.doi.org/10.1371/journal.pmed.1001242

${ }^{8}$ World Health Organization. Global Action Plan for the prevention and control of NCDs, 201W3-2020. World Health Organization, 2013.

${ }^{9}$ Faculty of Public Health, United Kingdom. FPH withdraws from responsibility deals. Available at: http://www.fph.org.uk/fph withdraws from responsibility deals. Accessed 29/06/2016

${ }^{10}$ Abbott, K. and Snidal, D. Taking Responsive Regulation Transnational: Strategies for International Organizations. Regulation and Governance, 2013;7:96. 